\title{
Anscombe and the Difference Rationality Makes
}

\author{
Eric Marcus \\ Auburn University \\ (Forthcoming in Anscombean Minds, eds. Haddock and Wiseman)
}

Anscombe famously argues that to act intentionally is to act under a description, and that "it is the agent's knowledge of what he is doing that gives the descriptions under which what is going on is the execution of an intention." ${ }^{1}$ Further, she takes 'knows' to mean that the agent can give these descriptions herself.' ${ }^{2}$ Since non-rational animals (hereafter 'animals') cannot describe anything, it would seem to follow that animals cannot act intentionally. However, she denies this, insisting that although animals cannot express intentions, they can have them. ${ }^{3}$ And she speculates that those who have a problem with this assume that the relevant description must "in some sense [be] written into something inside the agent."4 But this is an odd charge for her to make, given that she herself holds that a human agent can have an intention only if they can express it. In fact, the difficulty surrounding the idea of animal intention is not the result of any facile assumption, but indicative of a genuine philosophical puzzle, one that-if the argument to follow is correct-Anscombe's approach to action helps us resolve. To resolve it is to understand the difference that rationality makes to intentional action.

\footnotetext{
${ }^{1}$ Anscombe 2000, 87.

2 Anscombe 2000, 48.

3 Anscombe 2000, 5 .

4 Anscombe 1979, 221.
} 


\section{What the Difference is Not: Practical Knowledge}

How can we say that humans and animals both act intentionally while maintaining that linguistic expressibility is an essential characteristic of only human action? Matt Boyle has sketched the following approach to the general issue: we should attempt to articulate a determinate conception of how the human capacity for speech transforms and does not merely add to animal agency. Then we would have grounds for thinking of human action-together with the network of capacities that comprise it-as essentially, and not just accidentally rational.

Animals, on this sort of view, are a class of intermediate case between entities who admit only of 'reasons why' explanation and those admit also of 'reasons for' explanation. We can say why a house collapsed be appealing to a reason, but do not take the reason to be a reason for the house. We can say why a person opened a drawer by appealing to what was a reason for them. When a cat paws open a cupboard door and we say why by citing its knowledge of the location of the bag of treats, we appeal neither to a mere reason why nor to a full-blown reason for. The cat does not, to deploy a phrase common in philosophical discussions, grasp the reason qua reason. But how to interpret this phrase? I hope to make progress on the task through an examination of the parallel quandary concerning intentional action.

Martin Gustafsson has recently argued that Anscombe herself held a transformational conception of rationality: 
[Anscombe's] talk of how animal activities and powers are "transposed to a new key" in human life, due to "the intellective principle" of which an essential element is language, clearly suggests that she thinks the human way of having intentions is essentially linguistic even if the animal way of having intentions is not, and even if this difference between human and animal intentionality is not a matter of mere ambiguity in our use of the word "intention." 5

What is the ground for thinking that 'intentional' and its cognates have, if not univocal, then at least continuous sense in their application to human and animal action? Anscombe says this:

...[W]e describe what further [animals] are doing in doing something (the latter description being more immediate, nearer to the merely physical): the cat is stalking a bird in crouching and slinking along with its eye fixed on the bird and its whiskers twitching. The enlarged description of what the cat is doing is not all that characterises it as an intention....but to this is added the cat's perception of the bird, and what it does if it catches it. The two features, knowledge and enlarged description, are quite characteristic of description of intention in acting. Just as we naturally say 'The cat thinks there is a mouse coming', so we also naturally ask: Why is the cat crouching and slinking like that? and give the answer: It's stalking that bird; see, its eye is fixed on it. We do

5 Gustafsson 2016 210-211. 
this, though the cat can utter no thoughts, and cannot give expression to any knowledge of its own action, or to any intentions either. ${ }^{6}$

Human and animal action are both intentional in virtue of the fact that their actions admit of nested, teleologically-linked descriptions that radiate out from nearer to farther, from 'the merely physical' to those that reflect their further-from-the-'merely physical' purposes. Crucial is the role of perception and action in characterizing the contents of these distal descriptions. What transformative change, then, does the capacity for speech bring?

A tempting answer invokes practical knowledge. The difference between humans and animals, according to this thought, is that humans have a special kind of knowledge of their intentional action. Practical knowledge entails the ability to say what one is doing, but not on the basis of observation or evidence. Animals, the thought continues, don't know what they're doing. Practical knowledge might thus be seen as an aspect of the self-consciousness that characterizes the specifically rational form of animality.

Gustafsson seems to see it this way. In reviewing the characteristics of human action that might be said to turn on their expressibility, he says "human intention transgresses the biological boundaries that limit animal intention, and [] this transgression means that it interlocks with concepts such as freedom, selfconsciousness, and practical knowledge."7 By practical knowledge, he means this: "The language-using agent's conception of what she is doing-her practical knowledge of what she is doing-is "the cause of what it understands" (Anscombe 2000, 87), and thus

\footnotetext{
${ }^{6}$ Anscombe 2000, 86-87.

7 Gustafsson 2016, 232.
} 
plays as important a part in the constitution of her intention as the action she performs in order to reach the intended goal."8

But as tempting as it might be, this suggestion is wrong both exegetically and philosophically. When Anscombe endorses the Thomistic doctrine that practical knowledge is "the cause of what it understands", she means at least this much: the reality of an intentional action is posterior to the agent's conceiving of that action. If animals lack the capacity to form such conceptions, they are also incapable of the sort of intentional action elucidated in Intention. Thus, if practical knowledge were the exclusive possession of rational creatures, it would be hard to avoid the conclusion that we are, after all, simply equivocating when we speak of both humans and animals as acting intentionally.

Anscombe is clear in the passage above that animals are knowers: we see them as acting intentionally only insofar as we see them as possessing perceptual knowledge. And note too that she says that we give 'enlarged descriptions' of the cat's behavior despite the fact that it "cannot give expression to any knowledge of its own action...". She does not say that it has no such knowledge, only that it can give no expression to any knowledge. This precisely matches her view of animal intentions: animals have them but cannot express them. Thus, she finishes the sentence with “...or to any intentions either." Animals can give expression neither to their intentions nor to their knowledge of their intentions. But they have both.

Intention and practical knowledge, on her view, are inextricable. It will be instructive to deepen our understanding of their inextricability. Consider, for the sake

8 Gustafsson 2016, 225. 
of contrast, biological teleology. The right ventricle pumps blood to the lungs. This is the job of the right ventricle; if it doesn't do this, it fails. Pumping blood to the lungs isn't merely what it typically does, but what it is supposed to do; this aim normatively governs its behavior. Still, there is no temptation to think of pumping the blood to the lungs as something that the right ventricle intends to do. Why not? A key difference, as she emphasizes in the passage just excerpted, is that animals are guided in their action by perception. As such, they are knowers. It is because the cat has knowledge concerning the location of its prey that it can slink towards the tree in light of the fact that there is a bird sitting on one of its branches. One has the ability to $\mathrm{x}$ in light of the fact that $\mathrm{p}$ only if one knows that p. ${ }^{9}$ But among the facts an agent can act in light of is the fact that she is $\mathrm{x}$-ing, where $\mathrm{x}$-ing is her intentional action. This is practical knowledge. What makes this knowledge practical is that the agent has an ability to act in light of the fact that she is $\mathrm{x}$-ing not because she knows by observation that she is $\mathrm{x}$ ing but simply because $\mathrm{x}$-ing is what she is up to. In other words, part of what it is to be $\mathrm{x}$-ing is to be eligible to do various other things in light of the fact that one is $\mathrm{x}$-ing, and thus because one knows practically that one is x-ing. The cat, insofar as it is stalking the bird, is eligible to do various other things because it's stalking the bird. It can, e.g., slink instead of scramble. It takes a route that keeps it out of the sight-line of the bird because it is stalking the bird. Thus the cat must know it is stalking the bird. The ventricle pumps blood to the pulmonary artery because it's pumping blood to the lungs. It does the former in order to do the latter. But it does not do the former even partly in virtue of its knowledge that it is doing the latter. Yet this is precisely the situation of the

\footnotetext{
${ }_{9}$ See Hyman 1999 for an influential defense of this claim.
} 
cat: without practical knowledge, there would be no making sense of the fact that it is adopting various situationally-specific means in light of its end. Practical knowledge must itself be part of what is "transposed into a new key" by the acquisition of rationality.

Consider now the following claims of Boyle's, who in elaborating the idea of a transformative conception of rationality, says this:

It is perhaps even more obvious in this case that the generic notions of being an agent, doing something, and pursuing a goal apply to both rational and nonrational animals. What is perhaps less obvious is that agency, doing and goal-directedness take a different form in the rational case. Nevertheless, it is widely recognized that there is a sense of "doing something" that applies only to rational creatures: we are the only creatures that act intentionally. Furthermore, it is widely conceded that a condition of the applicability of ascriptions of doing in this distinctive sense is that the creature should be doing what it is doing knowingly, in virtue of exercising its power to determine what ends are worth pursuing and how to pursue them..$^{10}$

As should now be clear, I do not think that the rational/non-rational difference is properly marked by the presence/absence of intentions, or by the presence/absence of practical knowledge. But a slight modification of Boyle's final remark in this passage yields what I take to be central to resolving the puzzle of animal intention: only rational

10 Boyle 2012, 21-21 
creatures have practical knowledge in virtue of exercising a power to determine what ends are worth pursuing. Practical thought in humans is the exercise of such a power. It's not that humans do and animals don't act knowingly. It's that what it comes to for the human to act knowingly is different from what it comes to for the animal to act knowingly, on account of the difference in the power the exercise of which constitutes the relevant species of practical knowledge.

Gustafsson distinguishes human and animal intentions as follows:

[W]hereas the intentions manifested in the actions of a speechless brute are settled by biological norms and the surrounding circumstances, the human intention-action nexus is not thus determined but is instead characterized by the agent's capacity to set her own goals by means of language. This is the basic sense in which language is essential to human intentionality.... I can specify ends to myself, and this inscribes my actions in the sort of teleological patterns that are characteristic of human intentional action- patterns which cannot be accounted for merely in terms of biological norms and capacities. ${ }^{11}$

This might be misread as asserting that the key difference between human and animal action is a matter of the range of their possible intentions, but in fact the key difference is qualitative. It emerges most clearly in the distinctively human capacity for pure intentions. Gustafsson again:

${ }^{11}$ Gustafsson 2016, 225 
Anscombe says, "a man can form an intention which he then does nothing to carry out, either because he is prevented or because he changes his mind: but the intention itself can be complete, although it remains a purely interior thing” (2000, 9). If I am right, she would not say the same thing about a cat.... Anscombe thinks that a cat's intention to catch a bird cannot exist without some actual instrumental behavior, some actual "carrying out" of that intention. By contrast, she seems to be suggesting that in the human case, intentions do not require any such actual carrying out. ${ }^{12}$

I take this to be right, both exegetically and philosophically. The possibility of pure intentions is a function of the human capacity to set their own goals by means of language. Without this capacity, an aim exists only as manifested in behavior.

This claim does not entail that a restrained cat cannot, say, intend to catch a mouse. The cat presumably would still be struggling against the restraints, waiting to pounce, i.e., would be doing various things (however vainly) in order to catch the mouse. Nor does it mean that animal intention is, unlike human intention, reducible to behavior. The point is rather that the animal has no purely internalized practical consciousness, no practical orientation towards the world that does not manifest itself in what it does-where doing in the relevant sense encompasses waiting, hiding etc. ${ }^{13} \mathrm{~A}$

\footnotetext{
12 Gustafsson 2016, 225.

${ }_{13}$ Some might argue here that I am selling cats-or perhaps some other animals-short. Ultimately, however, my aim here is to draw a line, not to say who falls on what side of the line. There are, I contend,
} 
human, by contrast, can make up their mind to catch a mouse and at the same time put off doing anything in order to catch it until later. Human intentions are a kind of judgment, which, like judgments in general, extend into the future without staying 'on one's mind'. To put off doing something, or even thinking about doing something, is not tantamount to a change of mind or the abandonment of an aim.

It is the distinctively human capacity for judgment that Boyle has in mind when he speaks of practical knowledge as the exercise of a power to determine what ends are worth pursuing. The intention of a rational creature is a judgment. Specifically, it is the sort of judgment in which practical reasoning concludes: a judgment that an action is tobe-done. For the rational, practical knowledge is a function of the ability to reason about the good or, what is the same thing, to make practical judgments. We have knowledge of our intentions and actions because they are our practical judgments.

These remarks are, to be sure, programmatic; much detail would have to be added in order to make good on the promise of illumination. I've tried to do some of this in previous work, ${ }^{14}$ and I hope to make additional progress here. Negatively, the essential point thus far has been this: To see a cat as doing one thing in order to do another is to see it as acting with knowledge of what it is doing. Thus the transformation of practical knowledge is part of what must be understood to solve the puzzle of animal action. Practical knowledge is not the difference rationality makes. Positively, I have sketched the thought that human action is an actualization of a

two forms of agency, the rational and the non-rational. If this distinction does not correspond neatly to the that between the human and the non-human, so be it.

14 Marcus 2012, 2018. 
capacity to make judgments about what is to-be-done and that this confers on human intentions a kind of independence from behavior. This assessment will dovetail with reflections to follow on the distinctive character of the togetherness of the states of a rational mind.

\section{The Instrumental Law}

Our question is how the possession of language transforms intentional action. The transformation, I will argue presently, can be understood in terms of the different sources of unity in the practical consciousness of humans and animals. I will illustrate the point by discussing two variations of a law connecting an intended end with the means necessary to achieve it. Some version of this law holds quite generally. But what explains its holding in the case of humans and animals is different. In the human case, it holds in virtue of our possession of language and the capacity for normative selfdetermination that it confers. In animals, it holds because of the immanence of intentions in animal action.

Stephen Finlay argues for what I will refer to as the unqualified version of

The Psychological Instrumental LawuQ: It is impossible for an agent to intend an end and fail to intend what they believe to be the necessary means.

He says this:

So long as I have this belief in the necessity of going through the event of my turning on the light in order to reach the event of my spotting the 
kitten, my deliberative efforts to perform the necessary means to spotting the kitten will of necessity track the goal of turning on the light

- which simply means (given the identification of intending with tracking) that so long as I have this means-belief, my intention to perform the necessary means is an intention to turn on the light. So long as I believe that the necessary means to my intended end is z, I do indeed intend to do z. ${ }^{15}$

According to Finlay, once I know (or believe) that y-ing requires z-ing, then in intending to y, I thereby also intend to z. z-ing is now fused in my practical consciousness to y-ing. Instrumental knowledge (or belief), so long as it lasts, fuses a necessary means to the relevant end.

Christine Korsgaard rejects the 'fusing' picture, famously arguing that "there seem to be plenty of things that could interfere with the motivational influence of a given rational consideration. Rage, passion, depression, distraction, grief, physical or mental illness: all these things could cause us to act irrationally, that is, to fail to be motivationally responsive to the rational considerations available to us." ${ }^{16}$ Interestingly, she also says this: "The necessity [of rational considerations] may lie in the fact that, when they do move us-either in the realm of conviction or in that of motivation-they move us with the force of necessity. But it will still not be the case that they necessarily move us."17

\footnotetext{
15 Finlay 2009, 16. See Lee 2018 for a more recent defense of this sort of view.

${ }^{16}$ Korsgaard 1986, 13. See also Korsgaard 1997, 49.

${ }_{17}$ Korsgaard 1986, 14.
} 
In disputing the unqualified version of the Psychological Instrumental Law, Korsgaard is concerned primarily to argue for a normative, rather than metaphysical connection between an intended end and a necessary means. But in so doing, she also in effect, advances a qualified version of a metaphysically articulated Instrumental Law.

The Psychological Instrumental LawQ: It is impossible for an agent to intend an end and fail to intend what they believe to be the necessary means, unless they are being irrational.

In conceiving of rational considerations as operating with a kind of necessity, she opposes the idea that it is open to one who is being rational to recognize the reason and yet fail to comply. ${ }^{18}$ Hence, they move us with the force of necessity. Yet irrationality is a possibility, so they do not necessarily move us. There is more to this than the paradoxical-sounding claim that reasons necessarily move us except when they don't.

I will discuss the "realm of conviction" first, and then move to "the realm of motivation”. Note that a belief (like an intention) does not need to be in mind or actively guiding behavior in order to be held by a rational being. I take this to be a familiar point, often (though I think misleadingly) marked by the distinction between dispositional and occurrent belief. Second, whereas it is possible to hold contradictory beliefs, it is a condition of the possibility of doing so that they are not both in mind. That is, to understand someone as believing both that $\mathrm{p}$ and also that $\sim \mathrm{p}$, we need to

\footnotetext{
${ }^{18}$ However, as Lavin 2004 points out, she is not always as clear as she might be on this point. See also Fix, ms.
} 
understand one or the other belief as temporarily outside of the scope of the subject's scrutiny, on account of, e.g., distraction, self-deception, repression, etc.

Here's an example: An absent-minded professor is preparing a sack lunch for their children, placing folders and books in their bags when they receive a text-message announcing that school has been cancelled for the day due to classrooms having been flooded by the recent rains. They are briefly overwhelmed by frustration over being deprived of another day of writing and brood over how frequently the school seems to shut down for one reason or another-all the while continuing to ready their children's things for a day at school. To make sense of the latter, we need to understand them as believing that their children are going to school; to make sense of the former, we need to understand them as believing that their children are not going to school. They hold contradictory beliefs.

It is a crucial feature of the intelligibility of the absent-minded professor that their mind is in the relevant sense absent in relation to the behavior that grounds our ascription of one but not the other of their incompatible beliefs. This sort of lack of togetherness amongst their beliefs is required to make sense of belief-attributions such as: They believe that the kids are going to school (hence they're preparing sack-lunches) but they also believe that the kids are not going to school (hence they're mentally formulating an angry note to the principle concerning the frequency of unexpected school closings). We should say this: it is not necessarily true that we don't hold contradictory beliefs and also true that, in a sense, we can't. It is impossible to hold 
both that $\mathrm{p}$ and that $\sim \mathrm{p}$ clearly and distinctly. ${ }^{19}$ Let's call this The Psychological Law of Non-Contradiction ${ }_{\mathrm{Q}}{ }^{20}$

I will say more about this principle in a moment but let us first return to the Instrumental Law. Korsgaard's idea is that "rage, passion, depression, distraction, grief, physical or mental illness" can render one insensitive to one's aim and/or instrumental knowledge. Consider Alan, a philosophy graduate student. After a decade of slaving away on a dissertation, it is on the verge of completion. A wonderful job in the department of his dreams has improbably been offered to him on the condition that he defend his dissertation the following semester. To do so, he must submit the final version in the morning. But the last changes are proving difficult, and Alan cannot bear handing in an imperfect document. Furthermore, he is haunted by visions of public humiliation at the hands of one committee member in particular. His friends assure him that the defense is just a formality, and that the dissertation will be approved, but this doesn't help. They warn him that if he fails to produce, he will be expelled from the program and his academic career will be over, but this just makes it worse. At 3am, Adderall-addled Alan is overwhelmed by frustration and despair, and dumps a pot of coffee on his laptop, thereby destroying (what he knows to be) the only copy of his dissertation.

${ }_{19}$ Cf. Davidson, who in clarifying his proposal that contradictory beliefs requires a division in the mind says this: "I spoke of the mind as being partitioned, meaning no more than that a metaphorical wall separated the beliefs which, allowed into consciousness together, would destroy at least one" (Davidson 2004, 220).

${ }^{20}$ My discussion of this principle and its ontological correlate are deeply indebted to Kimhi 2018, though much of what I say here is opposed the views espoused there. 
Did Alan suddenly cease to know that the preservation of his laptop was required to get his dream job? Did he suddenly give up on his long- and deeply-held ambition? It is more plausible, I would think, that frustration and despair momentarily got the better of him, and that he did what he knew would undermine an intended end. That reasonable people could disagree about how to describe this case is a sign of the strain that the need for precision in philosophy puts on our ordinary concepts. On the one hand, he comes undone precisely because an end he can't relinquish requires an action he can't bear. On the other hand, we feel that in his agony he must have lost sight of his aim. But these are consistent: we lose sight of an aim-or a bit of knowledge-that we nonetheless possess. These are states that permit lapses into less than full consciousness. One can intend an end or have a piece of knowledge at a time when they are the farthest thing from one's mind.

Korsgaard holds that whereas it is not necessarily true that we do what (we know) is required to achieve our ends, when we do so, we do so because we must. It is impossible to clearly and distinctly know one's aim and the relevant instrumental fact and fail to act. This is not simply: it is impossible to fail to be moved by such reasons except when we aren't so moved. Suppose, by contrast, that we said not just "an adult human has 206 bones" but also "it is impossible for an adult human to have fewer than 206 bones, unless he had a limb amputated, or a bone removed, a congenital condition, or something weird like that." The latter is vacuous, since having had a limb amputated does not (nor do any of the other exceptions) explain how it's possible that someone could have fewer than 206 bones, it explains only how they actually came to have fewer than 206 bones. In the case of our qualified laws, the various psychological conditions explain self-contradiction and instrumental incoherence by postulating a psychological 
distortion that makes the irrationality intelligible. These are (or would be, if Korsgaard is right) conditions in which something interferes with the subject's appreciation of a rational requirement. It is (or would be) because their judgment is clouded by distraction, self-deception, repression, etc, that these sorts of irrationality are possible. Korsgaard may be wrong. But if she is, it is not because there is something amiss about the very idea of being moved by a reason with the force of necessity even though one might not have been so moved.

This will be my claim in what follows: The Psychological Instrumental Law governs both humans and animals, but the explanation of why is different, and this difference amounts to a difference in the nature of the unity of the practical consciousness of rational and non-rational beings. A characterization of this difference will provide a crucial element of an Anscombean account of the transformative effect of rationality on intentional action. ${ }^{21}$

\section{Rational Instrumental Coherence}

\footnotetext{
${ }^{21}$ There is a different strand of thought in Anscombe that one might bring to bear on the difference between human and animal action. In Anscombe 1982 she invokes a distinction among intentional acts between 'human actions' and the wider class of 'acts of a human being' (e.g., idly stroking one's beard). Only the former, she argues, are "under the command of reason". She might be read on this basis as holding that mere acts of a human being are the very same acts as those of an animal. I would resist this both as an interpretation of Anscombe-her focus in the essay is morality and not intention-and as a philosophical doctrine: it leaves the puzzle with which I began unresolved. But a discussion of the issue here would take us too far afield.
} 
Is it or is it not impossible to possess an aim while failing to intend what one knows to be necessary for achieving it? Korsgaard says "yes"; Finlay says "no". How one comes down on this issue will be determined at least in part by how one describes cases such as those of the absent-minded professor and Alan the philosophy grad student: whether belief or intention in such cases is judged deviant to the point of disqualification. I'm inclined to agree with Korsgaard, and for that reason and for the sake of rhetorical simplicity, I will from here on out simply assume she is right. But the crucial point, which I would argue holds regardless of how the Korsgaard/Finlay dispute shakes out, is this: the Psychological Instrumental Law (in whichever form you like) has different sources in rational and non-rational creatures. ${ }^{22}$

Rational creatures, I contend, are governed by the Psychological Instrumental Law in virtue of their grasp of

The Ontological Instrumental Law: It is impossible to achieve an aim if one fails to take the necessary means.

What makes it impossible for the means-intention and the end-intention of a rational creature to fall into incoherence, when they can't fall into incoherence, is that we grasp the Ontological Instrumental Law. Since animals do not grasp it, something else explains their not falling into instrumental incoherence.

\footnotetext{
${ }^{22}$ Korsgaard takes the possibility of failure to show that what explains the Psychological Instrumental Law is that we are guided by an Instrumental Norm (roughly: do what your ends require), a thesis that threatens a Humean picture of practical reason. But I take no stand here on the question of whether we are guided by such a norm, nor, for that matter, on the question of whether such a norm provides reasons for doing what our ends require. (But the answer to both is 'yes'.)
} 
Consider again The Psychological Law of Non-Contradiction ${ }_{Q}$. There are conditions under which it is impossible for us to hold contradictory beliefs. What explains this? Not that such a pair is the metaphysical analogue of matter and antimatter. Rather, it is the fact that without the distorting effects of the above-mentioned conditions, one would have to see that $\mathrm{p}$ and $\sim \mathrm{p}$ could not both be true. One cannot clear-headedly affirm and deny that p precisely because the act of affirmation itself depends on an understanding that affirmation and denial are incompatible acts. One only counts as affirming insofar as one understands what one is doing in affirming precisely as standing in opposition to denying.

Our beliefs are thus characterized by a form of togetherness whose exclusion of contradictories in paradigmatic instances is a function of our understanding of the impossibility of their joint truth. This amounts to a form of rational necessity. Necessity because what is at issue is genuine impossibility. Rational because what explains the necessity is our rationality: our grasp of the mutual exclusion of truth and falsehood. The Psychological Law of Non-Contradiction $\mathrm{Q}-$ it is impossible for a subject to believe both that $\mathrm{p}$ and $\sim \mathrm{p}$ unless they are being irrational-is thus explained by the rational agent's grasp of The Ontological Law of Non-Contradiction: it is impossible for both $\mathrm{p}$ and $\sim \mathrm{p}$ to be true.

The same holds in the realm of motivation. There are conditions under which it is impossible to intend an end and fail to intend what one knows to be the necessary means. What explains this? Without the distorting effects of the above-mentioned conditions, one would have to see that one will not achieve one's aim unless one pursues the relevant means. One would have unobstructed access to one's instrumental knowledge and also to the relevant aim. We cannot intentionally and clear-headedly 
both pursue $\mathrm{x}$-ing and avoid what's required for $\mathrm{x}$-ing, i.e., pursue and avoid $\mathrm{x}$-ing: these are incompatible acts. They are incompatible precisely because the (intentional) pursuit of any end requires a grasp of the fact that pursuit excludes avoidance. Here again we have rational necessity. When it is impossible to violate the Psychological Instrumental Law, it is because of our grasp of the Ontological Instrumental Law.

Suppose I'm boarding a train because I'm going to St. Louis, where the 'because' signals a rational connection. You ask: "Why are you boarding the train?" I answer: "because I'm going to St Louis." "Don't do it-trains are such a drag!". "But the airport has been shut down, the highways are closed, it's too far to walk, and this is the very last train." "Still, I advise against it." "So you are saying that I should just cancel the trip?" “No, just don't take the train.” At this point, you have simply ceased to make sense. What you are saying is incoherent. My rejection of your suggestion-that I go to St. Louis but don't take the train-is grounded in my rationality, in my understanding of means-end coherence. Even if Finlay is right and it is impossible to take up your suggestion, this impossibility has its source in our rationality. And if, as I have been assuming, Finlay is wrong and there is a possibility that I take up your suggestion-on account of one of the above-mentioned conditions-it is because our understanding loses its sway over our behavior.

More generally, one might say this: the source of the unity of the rational mind is a grasp of the fundamental conditions of theoretical and practical reality, which I have represented as the Ontological Instrumental Law and Ontological Law of NonContradiction. No creature that fails to grasp these conditions is capable of theoretical or practical judgment. Animals have no such grasp. I present no argument here for this latter contention. But note that even those who hold that the difference between human 
and animal belief is merely one of range would have to concede that the conceptual sophistication required for the grasp of these laws is outside the range of the nonrational. What explains the governance of animals by the Psychological Instrumental Law and the Psychological Law of Non-Contradiction must therefore be different.

\section{Non-Rational Instrumental Coherence}

Anscombe, recall, holds that animals can have intentions but not express them. Why should this be? Above, in elaborating Boyle and Gustafsson's Anscombe-inspired conception of practical rationality, we arrived at the following: practical rationality is the power to determine what ends are worth pursuing. And this power depends on the possession of language. This makes possible pure intentions, intentions that the agent "does nothing to carry out, either because he is prevented or because he changes his mind"23 The Korsgaardian characterization of someone like Alan is plausible because a disconnectedness from one's mental states is possible for rational creatures; one's intentions can be 'out of mind'. This is only possible for a being whose practical consciousness transcends their behavior, since it implies the possibility of losing sight of one's aims without their ceasing to be one's aims. It is also because human intentions transcend behavior that agents are capable of holding them up for scrutiny. Human intentions are actualizations of a power of articulation and thus also of critical scrutiny. They are judgments.

\footnotetext{
${ }^{23}$ Anscombe 2000, 9.
} 
Animal intention, by contrast "cannot exist without some actual instrumental behavior, some actual "carrying out" of that intention." ${ }^{24}$ Animal intentions, i.e., exist only as realized in their behavior. Insofar as an animal fails to pursue a necessary means, it follows that the animal lacks the relevant aim. The fusing picture is true of the animal mind. Instrumental incoherence requires the possibility of a separation in the mind between the aim and what's known to be necessary to achieve it, a possibility that is actualized in the human case by the various forms of irrationality that we have considered. But a cat cannot separate slinking right now and catching the bird, if it believes that the former is required for the latter. Such a separation cannot exist in the mind of the animal, whose inability to articulate makes it impossible. Animals do no repress their beliefs or aims, or become otherwise alienated from them. Animals of course can, or course be conflicted in their pursuit of end, but this conflict results at worst in wavering and reluctance, not in the back-burnering of an aim while another conflicting aim governs behavior. ${ }^{25}$ It is, in the end, the immanence of an animal's practical consciousness in its behavior that is the source of its unity. Language is a precondition of instrumental incoherence. Coherence, for animals, is a reflection of intentional immanence; for humans it is a function of rationality.

\section{Conclusion}

\footnotetext{
24 Gustafsson 2016, 225.

25 As Luca Ferraro pointed out to me, the crucial point is not that an animal mind can't be divided but that such divisions would require a fundamentally different sort of explanation, e.g. a split brain or something along those lines.
} 
My question in the foregoing was this: How does rationality transform animal agency? My answer is: by changing the source of the unity of practical consciousness. This, I submit, is progress on the puzzle of animal action. Still, the intentions of animals remain deeply puzzling. To give an action-explanation is to speak the mind of an agent. But how can one speak the mind of an agent whose mind is characterized by its unspeakability?26 Furthermore, if, as Korsgaard says, reasons operate on the will of a rational creature via their rationality, what plays the analogous role in the case of the non-rational? There is also a residual puzzle about practical knowledge. Perhaps, as I have argued elsewhere, practical knowledge of our action is just knowledge of a normative judgment. ${ }^{27}$ But then how should we understand the practical knowledge of animals?

I have relied, in characterizing rational agency, on an unexplicated notion of understanding, a capacity that I've linked to the possession of language. The plausibility of my argument depends on the idea that language confers upon us a capacity to grasp truths such as the two ontological principles discussed above and, more generally, to make judgments. Judgments are a kind of cognition that transcend behavior: they are what are held up for scrutiny in our explicit acts of reflection and deliberation. This line of thought has a venerable historical pedigree, but is generally viewed with hostility by contemporary philosophers of mind. It needs a robust defense. ${ }^{28}$

\footnotetext{
${ }^{26}$ I owe this way of putting the difficulty to Adrian Haddock.

27 Marcus 2018.

${ }^{28}$ See Marcus 2016.
} 
A final thought. I argued above that part of what explains the impossibility of violating the psychological laws is that the subject grasps the ontological laws. But the relevance of these laws to any specific circumstance depends upon the togetherness-inmind of the relevant mental states. That is, among the conditions that can explain why someone might believe both $\mathrm{p}$ and not-p, might both intend to $\mathrm{x}$ while failing to do what they know is necessary for $\mathrm{x}$-ing, is a failure to hold the two items together in consciousness: distraction and self-deception are two such conditions.

But what is it for mental states to exhibit togetherness in the relevant sense? The relevant sense is that these states are part of a single consciousness, a consciousness that takes in both at once. This is self-consciousness. By self-consciousness I don't simply mean the characteristic of individual mental states: that they are, as such, known (and known in a special way) by the believer. If it is impossible to hold a pair of mental states in mind at once, and the impossibility has its source in our understanding of the necessary falsehood of a conjunction or the undoability of one action without another, then it must be because, absent special circumstances, the subject has knowledge of not just the individual states they're in but also of their combination. And this knowledge is not itself a further state but rather a way of characterizing the togetherness. It is also consciousness of the self. For what one is conscious of is not simply a would-be disagreement but a would-be inconsistency. And this depends on consciousness of a unified, single subject. Ultimately, or so I would argue, the difference that rationality makes is self-consciousness. ${ }^{29}$

\footnotetext{
29 Versions of this paper were presented at the 2019 St. Louis Conference on Reasons and Rationality and the 2019 Conference on Theoretical and Practical Self-Consciousness at the University of Patras. Thanks
} 
to those audiences and especially to James Conant, Luca Ferrero, Jeremy Fix, Martin Gustafson, Adrian Haddock, Jennifer Hornsby, Anselm Mueller, Jack Samuel, John Schwenkler, and Sergio Tenenbaum. 


\section{References}

Anscombe, G. E. M. (1979). Under a description. Noûs 13 (2):219-233.

Anscombe, G. E. M. (1982). Medalist's Address: Action, Intention and 'Double Effect'. Proceedings of the American Catholic Philosophical Association 56:12-25.

Anscombe, G.E.M. (2000). Intention, Cambridge, MA.: Harvard University Press.

Boyle, Matthew (2012). Essentially rational animals. In Rethinking epistemology, ed. Guenther Abel and James Conant. Berlin, Germany: Walter de Grutyer: 395-428.

Davidson, Donald (2004). Problems of Rationality. Oxford: Clarendon Press.

Finlay, Stephen (2009). Against All Reason? Scepticism about the Instrumental Norm.

In Charles R. Pigden (ed.), Hume on Motivation and Virtue. Palgrave-Macmillan.

Fix, Jeremy David (manuscript). The Error Condition.

Gustafsson, Martin (2016). Anscombe's Bird, Wittgenstein's Cat. Philosophical Topics 44 (1):207-237.

Hyman, John (1999). How knowledge works. Philosophical Quarterly 49 (197):433-451. 
Kimhi, Irad (2018). Thinking and Being. Cambridge, MA: Harvard University Press.

Korsgaard, Christine M. (1986). Skepticism about practical reason. Journal of Philosophy 83 (1):5-25.

Korsgaard, Christine (1997). The Normativity of Instrumental Reason. In Garrett Cullity \& Berys Gaut (eds.), Ethics and Practical Reason. Oxford: Clarendon Press.

Lavin, Douglas (2004). Practical reason and the possibility of error. Ethics 114 (3):424457.

Lee, Woorram (2018). Willing the End Means Willing the Means: An Overlooked Reading of Kant. Ergo 16 (5): 419-444.

Marcus, Eric (2012). Rational Causation. Cambridge, MA: Harvard University Press; 2012.

Marcus, Eric (2016). “To Believe is to Know that You Believe”, dialectica 70, (3): 375405 .

Marcus, Eric (2018). "Practical Knowledge as Knowledge of a Normative Judgment”, Manuscrito 41 (4): 319-347. 